\title{
Awareness, Diagnosis, and Treatment of Depression
}

\author{
Larry S. Goldman, MD, Nancy H. Nielsen, MD, PhD, Hunter C. Champion, \\ for the Council on Scientific Affairs, American Medical Association
}

OBJECTIVES: To review recent findings on the epidemiology, burden, diagnosis, comorbidity, and treatment of depression, particularly in general medical settings; to delineate barriers to the recognition, diagnosis, and optimal management of depression in general medical settings; and to summarize efforts under way to reduce some of these barriers.

DESIGN: MEDLINE searches were conducted to identify scientific articles published during the previous 10 years addressing depression in general medical settings and epidemiology, co-occurring conditions, diagnosis, costs, outcomes, and treatment. Articles relevant to the objective were selected and summarized.

CONCLUSIONS: Depression occurs commonly, causing suffering, functional impairment, increased risk of suicide, added health care costs, and productivity losses. Effective treatments are available both when depression occurs alone and when it co-occurs with general medical illnesses. Many cases of depression seen in general medical settings are suitable for treatment within those settings. About half of all cases of depression in primary care settings are recognized, although subsequent treatments often fall short of existing practice guidelines. When treatments of documented efficacy are used, short-term patient outcomes are generally good. Barriers to diagnosing and treating depression include stigma; patient somatization and denial; physician knowledge and skill deficits; limited time; lack of availability of providers and treatments; limitations of third-party coverage; and restrictions on specialist, drug, and psychotherapeutic care. Public and professional education efforts, destigmatization, and improvement in access to mental health care are all needed to reduce these barriers.

KEY WORDS: depression; mental health; knowledge, attitudes, practice; health service accessibility; comorbidity. J GEN INTERN MED 1999; 14:569-580.

$\mathbf{T}$ his report reviews recent findings on the epidemiology, burden, diagnosis, comorbidity, and treatment of depression, particularly in general medical settings; describes barriers to the recognition, diagnosis, and optimal management of depression in general medical settings; and summarizes efforts under way to reduce these barriers. The American Medical Association's Council on Scientific Affairs produced a series of reports on depression in $1991 .^{1}$

\section{METHODS}

MEDLINE searches were conducted to identify scientific articles published during the previous 10 years addressing depression in general medical settings and epidemiology, co-occurring conditions, diagnosis, costs, outcomes, and treatment. Articles relevant to the objective were selected and summarized.

Major depression is the depressive disorder on which most research has been conducted. Other depressive disorders, such as dysthmyic disorder ("chronic" depression) and mixed depressive-anxiety states, are also common in general medical settings but have been studied far less. Similarly, most research has been done in adult populations; this report notes a few instances of information about children. Except for comoribidity, most of the research in this area has been in primary care settings rather than in more specialized medical environments; most research on treatment has been conducted in specialty mental health settings.

\section{EPIDEMIOLOGY IN GENERAL MEDICAL SETTINGS}

Depressive disorders are common in the general population, with a point prevalence of about $2 \%$ to $4 \%$ for major depressions ${ }^{2}$ and about a $20 \%$ lifetime risk for the development of major depression or dysthymic disorder. ${ }^{3,4}$ The rate of depression among women is 2 to 3 times that of men. ${ }^{5}$ These findings are based on large community surveys using structured interviews. Of those seeking help for depression in the United States, nearly three fourths go to a primary care physician rather than to a mental health professional. The most common presentation in primary care is not dysphoria but rather complaints of sleep disturbance, fatigue, or pain. ${ }^{6}$ Overall, 5\% to $10 \%$ of ambulatory primary care patients and $10 \%$ to $14 \%$ of medical inpatients suffer from major depression. ${ }^{7}$ One study in a general internal medicine practice treating

Received from the Council on Scientific Affairs, American Medical Association, Chicago, Ill (LSG, NHN, HCC).

Address correspondence and reprint requests to Dr. Bresolin: Secretary to the Council on Scientific Affairs, American Medical Association, 515 N. State Street, Chicago, IL 60610. 
a diverse population found that $10 \%$ of the patients had diagnosable depressive disorders, while $11 \%$ had a disorder with depressive symptoms that did not fit into any standard diagnostic categories $^{8}$; this underscores the high prevalence of depressive complaints that do not fit into current diagnostic schemes.

Another study examined more than 1,000 primary care patients whose diagnostic screen was positive for major depression and who then underwent a psychiatric evaluation. ${ }^{9}$ Seventy percent of these patients were suffering from major depression that could be treated in a primary care setting, $13 \%$ had major depression but required specialty sector care, and $17 \%$ had conditions other than major depression. Of those with major depression suitable for primary care treatment, nearly $75 \%$ had suffered at some time during their life from an additional Diagnostic and Statistical Manual of Mental Disorders, 4th ed. (DSM-IV) axis I disorder (most commonly generalized anxiety or panic disorder), ${ }^{10}$ and $68 \%$ were felt to have an axis II (personality) disorder. A high percentage had experienced episodes of major depression prior to the study episode. This study illustrates both benefits and limitations of screening, the predominance of cases suitable for primary care setting treatment, the need to inquire about past history of depression, and the high rates at which other psychiatric disorders co-occur with depression.

\section{BURDEN}

Among the well-known burdens caused by depression are patient suffering, family distress and conflict, impaired cognitive development of young children in cases of postpartum depression, ${ }^{11}$ and the strikingly increased risk of suicide. More recent studies have examined the impact on functioning and the economic burdens. The Medical Outcomes Study looked at patient physical functioning in several chronic diseases. Patients with depression had functioning scores about the same as those with advanced coronary artery disease, scores that were in turn lower than all other conditions studied, including hypertension, diabetes mellitus, and arthritis. ${ }^{12}$ This impairment in functioning, when coupled with the high prevalence, chronic or relapsing course, and frequent early onset, led a group of World Health Organization researchers to conclude that unipolar major depression is the leading cause of disability worldwide. ${ }^{13}$ Functional improvement occurs with effective treatment.

Costs of depression in the United States have been estimated at $\$ 43$ billion per year. ${ }^{14}$ Only $30 \%$ of the cost is from direct medical care; the remainder is from premature death and impaired workplace productivity. The economic cost to employers is estimated at $\$ 6,000$ per depressed worker per year. ${ }^{15}$

The effects of depression on consumption of medical care are striking. When the diagnosis of depression is missed, the search for physical explanations of symptoms causes unnecessary increases in medical utilization rates.
When depression co-occurs with other general medical conditions, patient adherence to treatment is worsened, chances for improvement or recovery from the other condition are lessened, and health care costs are further increased. ${ }^{16}$ One study in a large group HMO compared two groups of "high utilizers" (i.e., patients whose annual medical expenses were above the HMO median). Costs for high utilizers who were depressed were $\$ 1,500$ higher per year than for those who were not depressed. ${ }^{17}$ Health care costs in patients with depression and co-occurring medical illness are increased even when the nature and severity of the medical condition are controlled. ${ }^{18,19}$

\section{DIAGNOSIS}

The diagnosis of major depression is fundamentally clinical. As with most psychiatric disorders, it is made on the basis of a careful clinical interview and mental status examination. Considerable evidence suggests that such an interview is comparable in sensitivity and specificity to many radiologic and laboratory tests commonly used in medicine. The criteria in the DSM-IV (Table 1) are generally considered the standard diagnostic approach. Major depression is a syndromal diagnosis: on the basis of the patient's medical history and physical examination, it may be appropriate to consider other psychiatric disorders (obsessive-compulsive disorder, panic disorder, bulimia nervosa, dementia), general medical conditions, medications, or a substance use disorder as etiologic and to pursue relevant diagnostic investigations.

A number of screening tools are available to help physicians identify patients most likely to be depressed. As with most screening instruments, they tend to be fairly sensitive but not too specific for identifying depression. Most authors suggest screening when the physician has some a priori suspicion of depression, typically a specific depressive symptom, unexplained physical symptoms, impaired functioning, or subjective distress out of proportion to a known general medical condition, or another psychiatric disorder. Physicians must interpret specific screening results correctly and appreciate the need to carry out further clinical assessment. No preventive service guide calls for depression screening in asymptomatic individuals. ${ }^{20,21}$

Long-established, symptom-oriented patient self-report screens include the General Health Questionnaire, ${ }^{22}$ the Beck Depression Inventory, ${ }^{23}$ the Symptom Checklist, ${ }^{24}$ the Inventory of Depressive Symptoms, ${ }^{25}$ and the Zung Depression Scale. ${ }^{26}$ Scores above a predetermined cutoff suggest the need to perform a more comprehensive evaluation for depression. These screens have sensitivities of $70 \%$ to $85 \%$ and specificities of about $80 \%$. The Center for Epidemiologic Studies Depression scale ${ }^{27}$ and the shortened Geriatric Depression Scale ${ }^{28}$ have been proposed as particularly valuable in the elderly. ${ }^{29}$ These tools are designed simply to produce a depression rating (severity) score; however, two more recent instruments, the 
A. Five (or more) of the following symptoms have been present during the same 2-week period and represent a change from previous functioning; at least one of the symptoms is either (1) depressed mood or (2) loss of interest or pleasure. ${ }^{\dagger}$

1. Depressed mood most of the day, nearly every day, as indicated by either subjective report (e.g., feels sad or empty) or observation made by others (e.g., appears tearful). Note: In children and adolescents, can be irritable mood.

2. Markedly diminished interest or pleasure in all, or almost all, activities most of the day, nearly every day (as indicated by either subjective account or observation made by others).

3. Significant weight loss when not dieting or weight gain (e.g., a change of more than $5 \%$ of body weight in a month), or decrease or increase in appetite nearly every day. Note: In children, failure to make expected weight gains.

4. Insomnia or hypersomnia nearly every day.

5. Psychomotor agitation or retardation nearly every day (observable by others, not merely subjective feelings of restlessness or being slowed down).

6. Fatigue or loss of energy nearly every day.

7. Feelings of worthlessness or excessive or inappropriate guilt (which may be delusional) nearly every day (not merely selfreproach or guilt about being sick).

8. Diminished ability to think or concentrate, or indecisiveness, nearly every day (either by subjective account or as observed by others).

9. Recurrent thoughts of death (not just fear of dying), recurrent suicidal ideation without a specific plan, or a suicide attempt or a specific plan for committing suicide.

B. The symptoms do not meet criteria for a Mixed Episode.

C. The symptoms cause clinically significant distress or impairment in social, occupational, or other important areas of functioning.

D. The symptoms are not due to the direct physiologic effects of a substance (e.g., a drug of abuse, a medication) or a general medical condition (e.g., hypothyroidism).

E. The symptoms are not better accounted for by Bereavement, i.e., after the loss of a loved one, the symptoms persist for longer than 2 months, or are characterized by marked functional impairment, morbid preoccupation with worthlessness, suicidal ideation, psychotic symptoms, or psychomotor retardation.

*From American Psychiatric Association. ${ }^{10}$

${ }^{\dagger}$ Note: Do not include symptoms that are clearly due to a general medical condition, or mood-incongruent delusions or hallucinations.

Symptom-Driven Diagnostic System for Primary Care ${ }^{30}$ and the Primary Care Evaluation of Mental Disorders, ${ }^{31}$ are diagnosis-oriented, patient-administered screens that are supplemented by a clinician-driven diagnostic module if any of the patient screens are positive. These instruments probe for several different psychiatric disorders, including major depression. There also are other symptom checklists or inventories. All screens require diagnostic confirmation by a careful clinical interview.

The primary care version of DSM-IV provides in abbreviated form the DSM-IV diagnostic criteria of the mental disorders most commonly seen in primary care settings, including depression. ${ }^{32}$ It also contains symptom-driven algorithms to move from a patient's complaint to a specific diagnosis. A pediatric version has been developed by the American Academy of Pediatrics. ${ }^{33}$ The World Health Organization has developed a primary health care version of the International Classification of Diseases dealing with mental disorders (ICD-10 PHC, chapter 5) that contains cards with information about the common complaints, diagnosis, and management of 24 common psychiatric disorders. ${ }^{34}$

Several aspects of the DSM approach may be problematic in a medical setting. A number of the symptoms are somatic. Although the diagnostic criteria give equal weighting to all nine symptoms, clinicians often fail to consider depression as part of a differential diagnosis of the patient's chief complaint unless the complaint itself is of dysphoria or the patient is observably and notably sad. Patients may tend to emphasize physical symptoms because these are most troubling, because they are reluctant to disclose emotional distress, or because they believe the physician will be most interested in or helpful for those symptoms. At times, it may be difficult to determine whether any particular symptom is caused by a depression or by another medical disorder.

\section{COMORBIDITY}

Depression occurs frequently with anxiety disorders and with substance use disorders, including alcoholism. More recent research highlights the relation between nicotine addiction and depression. ${ }^{35}$ Diagnosis of co-occurring depression and substance abuse is complicated, as either condition may overshadow the other. A number of recent textbooks and review articles are devoted to issues of diagnosing and treating depression and other psychiatric disorders in general medical populations. ${ }^{36-38}$

Recent studies and reviews confirm the high rates of depression and its morbidity seen in many general medical conditions, especially those that affect the central nervous system. Table 2 summarizes some of the studies examining the rates of depression in various medical conditions.

Advanced age also may be an important factor that exists concurrently with depression. Depression in the 
Table 2. Rates of Depression Co-Occurring with Other Medical Conditions

\begin{tabular}{|c|c|c|}
\hline Condition & Depression Rate, \% & Comment \\
\hline Myocardial infarction & $20-40$ & In 6 months after myocardial infarction \\
\hline Parkinson's disease & 40 & About half major depression, half dysthymia \\
\hline Huntington's disease & 50 & About half major depression, half dysthymia \\
\hline Alzheimer's disease & $30-35$ & Generally early in illness course \\
\hline Stroke & $25-50$ & Major depression in first year after stroke; risk correlates with site of lesion \\
\hline Cancer & $3-50$ & Varies with type, location, stage \\
\hline $\mathrm{HIV} / \mathrm{AIDS}$ & $10-20$ & In later stages, $4 \%-11 \%$ in asymptomatic seropositive \\
\hline Rheumatoid arthritis & 12 & Up to $42 \%$ lifetime \\
\hline Diabetes mellitus & $14-18$ & $33 \%$ lifetime \\
\hline Chronic pain & 30 & $60 \%$ lifetime \\
\hline Disabling tinnitus & 60 & 75\% lifetime \\
\hline End-stage renal disease & $5-22$ & \\
\hline Spinal cord injury & 37 & \\
\hline
\end{tabular}

elderly may be particularly hazardous and costly if untreated, and it also may be more complicated to treat. ${ }^{39-41}$ Finally, untreated depression in the presence of terminal medical illness is one of several psychosocial factors associated with patient requests for physician assistance in dying. ${ }^{42}$

\section{TRENDS IN TREATMENT}

Recent trends in the treatment of depression have been driven by scientific advances as well as changes in the practice environment. Over the past 10 years, nine newly marketed antidepressants (fluoxetine [Prozac], sertraline [Zoloft], paroxitene [Paxil], bupropion [Wellbutrin], venlafaxine [Effexor], fluvoxamine [Lu-vox], nefazodone [Serzone], mirtazapine [Remeron], and citalopram [Celexa]) were released in the United States. These drugs are structurally and pharmacologically quite different from the older tricyclic and monoamine oxidase inhibitor agents. For the most part, these drugs exhibit a more benign side effect profile, a simplified dosing strategy, better patient adherence, and a lower risk of death in overdose situations compared with the older drugs. As a result, they have quickly been adopted in medical settings, and several are among the most commonly prescribed drugs in all of medicine. These newer drugs do, however, continue to demonstrate the delay in full therapeutic action (several or more weeks) seen with older drugs, they generally lack a clear relation between serum drug level and therapeutic response, and some pose risks of significant drugdrug interactions with other medications. ${ }^{43}$

Parallel advances in the development and testing of psychotherapies have occurred as well. Cognitive behavioral and interpersonal psychotherapy, which are both structured and time-limited in nature, have been shown to be equal in efficacy to antidepressant medication for mild-to-moderate, nonbipolar, nonpsychotic major depression, the type seen most commonly in general medical settings. ${ }^{44}$ Such therapies offer a genuine alternative to patients intolerant of or averse to using antidepressant medications, to those who prefer psychotherapy, and to pregnant or nursing women. It is still uncertain whether combining pharmacotherapy and psychotherapy yields better outcomes than either form of treatment alone. ${ }^{45,46}$ The exact role of other forms of psychotherapy (e.g., behavioral, marital/family, group, psychodynamic) in depression also remains unclear.

These specific therapies for major depression are different from the general supportive care offered by many physicians. Although such support may be vital to the doctor-patient relationship, may encourage medication adherence, and can be helpful to the patient, there is no empirical evidence of its efficacy as a specific treatment modality. Few nonpsychiatrist physicians are trained in cognitive-behavioral or interpersonal psychotherapy, although other specific forms of counseling by the primary care physician may also improve outcomes. ${ }^{47,48}$ Primary care physicians most commonly prescribe medications themselves as a sole treatment modality, offer a few sessions of supportive psychotherapy, or refer patients to mental health practitioners for psychotherapy (either as sole therapy or in conjunction with primary care antidepressant prescribing, so-called split treatments). The impact on outcomes of these different provider approaches is not well understood. ${ }^{49}$

A further development in depression treatment is the growing appreciation of depression as a chronic, often recurrent illness. At least $50 \%$ of those who experience an episode of major depression without a co-occurrent general medical condition will go on to have another, and after several such episodes the risk of future recurrences probably exceeds 90\%. In addition, while most patients make a full recovery from any particular episode (with or without treatment), about one fifth to one third have a residual persistence of symptoms or impairment in functioning or both. ${ }^{50}$ Thus, interest has increased in using medications prophylactically (after a likely episode recovery but in anticipation of a subsequent one), particularly after the patient has experienced several episodes. In addition, studies have sought to clarify whether any specific 
psychotherapeutic interventions afford a protective effect against future episodes (i.e., after cessation of psychotherapy or when it is provided at infrequent intervals). ${ }^{51}$ Much of the information on illness prevalence, course, and treatment efficacy was reviewed, synthesized, and published as a set of treatment guidelines on depression for primary care settings by the Agency for Health Care Policy and Research (AHCPR). ${ }^{52}$

Several trends also have emerged as a result of changes in health care delivery systems. There is growing appreciation of the important role of the primary care sector in caring for those with a variety of psychiatric illnesses. ${ }^{53}$ The "gatekeeper" role has come to include an increased pressure on primary care physicians to diagnose and treat depression themselves. This pressure is both clinical (they can provide more integrated care) and economic (to limit more costly specialty sector referrals). As with other illnesses, patients with uncomplicated depression are likely to receive care from their primary care physician, while those with complex (e.g., bipolar, psychotic, suicidal, other co-occurrent psychiatric disorders such as substance use disorders) or treatment-refractory illnesses, or those requiring specialized treatments (e.g., electroconvulsive therapy, light therapy, cognitive-behavioral psychotherapy) may be followed in the specialty mental health sector.

There has been a dramatic rise in recent years of mental or behavioral health "carve outs," where an organizational entity contracts with a managed care organization or other general health provider to provide all services for patients identified as in need of mental health services. This entity may be clinically or geographically distinct from the primary medical care setting. The proposed advantage of this approach is to guarantee an expert set of specialized clinicians and services that can care for all of a patient's mental health problems (e.g., depression, substance abuse, personality disorders) and provide an optimal level of access and treatment setting (e.g., outpatient office, partial hospital, detoxification setting, inpatient hospital). Potential disadvantages center on the fact that such care is not integrated into the patient's general medical care. Thus, the patient may need to utilize different facilities, the record-keeping system is separate, and the feedback loop between referring and treating clinician is stretched or nonexistent. Unlike traditional practice in which the referring physician selects the consultant (often based on previous shared experiences), carved-out care seldom allows the primary care physician to decide to whom he or she is sending the patient or even which type of mental health professional the patient will see. However, to date there has been little research to inform this debate.

\section{MANAGEMENT IN GENERAL MEDICAL SETTINGS}

A number of studies indicate that about half of those with psychiatric disorders (including depression) are detected in primary care settings. ${ }^{54}$ Only about half of these receive any treatment, and that occurs largely (50\% to $75 \%$ of the time) in the primary care setting rather than in the mental health care system.

A multisite outpatient study of health care system factors in the recognition and care of depressed patients found that $46 \%$ to $51 \%$ of these patients were recognized by medical clinicians, while $78 \%$ to $87 \%$ were recognized by mental health specialists. ${ }^{55}$ Among the medical clinicians, depression was less likely to be recognized or treated under a prepaid system than under fee-for-service care. Nonetheless, depression outcomes in the general medical sector were similar under prepaid and fee-for-service care (because rates of treatment were similarly low to moderate in both payment systems). ${ }^{56}$

Several studies have examined physician factors that may influence recognition of depression. In one study, high physician interest in psychosocial issues did not correlate with the type of interviewing behaviors necessary to diagnose depression. Several specific interviewing behaviors did, however, lead to great recognition of depression, including open-ended questioning, periodically summarizing the patient's information, and responding to nonverbal and emotional patient cues. ${ }^{57}$ Robbins and colleagues found that primary care physicians who were more sensitive to affective and nonverbal patient cues made more psychiatric diagnoses, and physicians who tended to blame patients for their depression made fewer and less accurate diagnoses. ${ }^{58}$ Overall, these authors found that false-positive psychiatric diagnoses were uncommon.

A few studies have examined the impact of recognition on patient outcomes. Simon and VonKorff screened patients attending a primary care clinic and interviewed those with positive depression screens: they found that unrecognized and untreated cases had a milder selflimited illness. ${ }^{59}$ As a result, they concluded that a focus on increased recognition might not improve overall outcomes significantly. The Groningen Primary Care Study also found that recognition of psychological disorders by primary care physicians was not associated with better patient outcomes, and concluded that recognition was necessary but not sufficient unless primary care physicians had the skills or resources to provide appropriate treatments after making a diagnosis. ${ }^{60}$

Katon and Gonzales reviewed all randomized trials of mental health interventions in primary care settings developed by consultation-liaison psychiatrists. ${ }^{61}$ They too concluded that screening interventions and feedback to the primary care physician somewhat increased recognition and treatment of depression, but that the effect on patient outcomes was unclear. In general, although the link between diagnosis and treatment of depression may seem conceptually clear, in practice these tasks are not invariably linked. ${ }^{62}$

A recent review of studies of unrecognized psychiatric illnesses in general medical outpatient settings found that: (1) half of the disorders were unrecognized; (2) the natural history of unrecognized depression suggested no 
worsening of course; and (3) interventions to teach physicians led to greater recognition and treatment but had little short-term effect on symptoms or health care use. ${ }^{63}$ The review concluded that efforts to increase recognition alone that are not connected to strategies to improve management may not reduce patient suffering or decrease health care costs. Nonetheless, this conclusion may be less applicable over a longer period of time, as some milder depressions may worsen slowly over time.

Four studies have examined the rates of recognition of psychiatric disorders in children in primary care settings: the percentage of cases recognized ranged from $17 \%$ to $59 \% .^{64-67}$ Insufficient data exist to reach any conclusions about the clinical or economic significance of such nonrecognition in children.

Even when patients' depression is recognized, treatment provided is highly variable. One study on high utilizers of one HMO's primary care medical services (a patient group known to be at high risk of depression) found that half of these patients were clinically depressed, yet only $45 \%$ of the depressed high utilizers had received an antidepressant during the preceding year. ${ }^{68}$ Only one fourth of those receiving an antidepressant received a dose or duration of treatment that would be considered adequate by relevant practice parameters.

Another study that looked at depression treatment in a variety of different primary care settings found that only $11 \%$ of mildly and $29 \%$ of markedly depressed patients received any antidepressant. ${ }^{69}$ In that same study, only about one third of all of the patients cared for by psychiatrists received any antidepressant, and only $41 \%$ received an adequate dose. In another study in a group of academically affiliated primary care offices, physicians were explicitly informed by investigators of patients with major depression and urged to provide treatment. ${ }^{70}$ Only about three fourths of the patients were treated, $60 \%$ of them with antidepressants; only $43 \%$ of those prescribed antidepressants received them in amounts consistent with AHCPR guidelines.

Psychotherapy or counseling is even scarcer in primary care settings. In the Medical Outcomes Study conducted at multiple sites, less than half of depressed patients in the general medical sector settings received 3 minutes or more of counseling from their primary care physicians. ${ }^{71}$ Counseling rates were lower under prepaid than fee-for-service plans.

A limited number of studies have examined the effect of increasing treatment to depressed patients by various methods. One small uncontrolled study examined high utilizers who were depressed and who were treated by the primary care physician with antidepressants following a study protocol. There were significant reductions in symptoms, improvements in quality-of-life measures, and increases in work performance. Overall general medical costs fell by $50 \%$, and even when depression treatment costs were figured in, there remained a modest cost saving. ${ }^{72}$
Sturm and Wells estimated the effects of restricting access to specialty care and predicted that shifting patients away from mental health specialists decreased costs but worsened patients' functional outcomes. ${ }^{73}$ They suggested that there should be quality improvement in the general medical sector rather than changing the primary care-specialty care mix. Schulberg and colleagues attempted to have primary care physicians follow AHCPR guidelines for treatment of depression. ${ }^{74}$ They found that doing so is feasible but challenging, that keeping patients in treatment is problematic (only 33\% completed a full treatment regimen per the guidelines), and that physicians need to be more flexible than the guide regimens suggest. ${ }^{75}$ There was a $70 \%$ recovery at 8 months when AHCPR guidelines were adhered to versus a 20\% recovery among patients receiving usual care, suggesting high effectiveness of the guidelines. In those recovering, functional improvements occurred across a broad range of domains in addition to symptomatic improvement. ${ }^{76}$

Two recent studies looked at a multifaceted intervention that integrated a psychiatrist or psychologist into the primary care area. The intervention consisted of a structured program of patient education, behavioral counseling, improved psychopharmacologic management, drug refill tracking, and physician education. This approach led to significant improvement in depression, patient satisfaction, medication adherence, and cost-effectiveness when compared with usual care, but only for those with major depression and not for those with minor (milder) depression. ${ }^{77-79}$

\section{BARRIERS TO OPTIMAL MANAGEMENT}

\section{Recognition Barriers}

Because of the stigma still attached to psychiatric illnesses, many patients are reluctant to acknowledge to themselves or their physicians that they are experiencing emotional distress. Patients may deny or minimize symptoms, rationalize them as expectable because of life stresses or as due to other general medical problems, believe them to be failures of will or moral shortcomings, or not see them as within the physician's purview or capabilities. These attitudes may be reinforced by familial or cultural beliefs. Similarly, patients may be reluctant to disclose information they fear could be included in insurance or employment records; they may be especially concerned about having a psychiatric diagnosis recorded. ${ }^{80}$

Attention also has been called to physician deficits in this area. ${ }^{81,82}$ Some physicians harbor the belief that depression is not a "real" illness. Some believe that depression reflects a personal shortcoming or laziness and is thus something the patient could improve with more effort, willpower, or "positive thinking." Others are doubtful about the existence of depression as a clinical entity because of the absence of confirmatory laboratory or radiologic studies. These doubts may take different forms, 
from simply never inquiring about depressive symptoms to having an unduly high threshold for considering depression in the differential diagnosis of a patient's chief complaint.

Even when attitudes are appropriate, some physicians lack the requisite skills to properly elicit the relevant history. ${ }^{83}$ Many adopt a highly focused closed-ended interviewing technique that may prevent patients from bringing up affectively laden or psychosocial material. Failure to recognize nonverbal cues and to ask follow-up questions in response to indications of distress are also potential impediments to obtaining an appropriate history. Some physicians fail to offer empathic, supportive comments during the interview, cues that patients may interpret as lack of interest or unwillingness to discuss these concerns. Finally, some physicians, uncomfortable with displays of affect, may consciously or unwittingly steer the interview toward less difficult areas.

Differences in age, gender, or cultural background may result in barriers in the interaction between patient and physician. One of the most common interactional barriers is the medicalization of presenting complaints. ${ }^{84}$ As discussed above, $50 \%$ to $70 \%$ of depressed patients will present with somatic rather than psychological complaints. ${ }^{85}$ Patients may believe or hope that something physical is wrong, the cause will be found, and they will be healed. Because of stigma issues, there may be a potent investment on the part of the patient in keeping the focus on the somatic complaints. The physician, too, may feel more comfortable in the physical realm, and the assessment will emphasize these complaints. This focus in medical training, which covertly reinforces a more limited biomedical rather than biopsychosocial model, has been referred to as the "hidden medical curriculum." 86 Symptoms that are not physical in nature (e.g., sadness, guilt, hopelessness) may not be asked about or voiced by the patient, and the recognition that the patient has a psychiatric disorder eludes both patient and physician. This appears to be especially the case among older patients.

Medicalization and other barriers may be compounded by the increasing time demands of an office visit. Physicians may be reluctant to elicit affectively laden information that can require more time to explore and to reach closure. Patients also may be reluctant to discuss topics for which they know insufficient time may be available. In addition, physicians often have a multiplicity of tasks during an office visit, such as assessment and ongoing management of known general medical problems, prevention and health maintenance, and paperwork. Limited remuneration for the time spent on assessing depression may influence the outcome.

In addition, the lack of appropriate performance standards for depression in managed care and other medical settings limits knowledge of actual practice and impedes feedback to clinicians, administrators, consumers, and purchasers of health care.

\section{Diagnostic Barriers}

One group of barriers concerns physician appraisal of the patient's willingness to consider having a psychiatric disorder. Physicians may not wish to compromise patient confidentiality or may fear offending patients or families by making a psychiatric diagnosis. At times, physicians may accurately assess that a patient is simply not ready to accept a diagnosis (e.g., by observing defensiveness during relevant inquiries), so they defer a full assessment decision about the diagnosis.

Other barriers pertain to appropriate diagnostic criteria. The DSM-IV criteria were developed largely in psychiatric settings, and some have questioned their applicability to primary care and other medical situations. One controversy concerns patients who meet some but not all criteria for major depression, a group encountered far more often in primary care than psychiatric settings. Another problematic group are those with mixed symptoms of depression and anxiety that fall short of DSM-IV thresholds for a disorder. Patients in either of these groups may be symptomatic and have functional impairment but, because they fail to meet full diagnostic criteria, may not be appropriately diagnosed or treated.

A third set of factors relates to inadequate physician knowledge about depression. Physicians may be unfamiliar with the diagnostic criteria and thus may not appreciate the differences between transient sadness, bereavement, and a clinical illness. Others understand the diagnostic criteria but fail to appreciate the import of the illness: they may believe it will remit spontaneously, that it is understandable in the context of the patient's life, or that it does not cause much suffering or dysfunction. Thus, they may not perform a careful diagnostic assessment because they would not be inclined to treat anyway.

The complexities of some clinical situations also may impede an accurate diagnosis. Symptoms of certain concurrent general medical conditions may overlap those of depression and may be attributed to the concurrent condition. A similar attribution problem may occur when a patient is taking medications that can cause depressive symptoms. When patients have another psychiatric disorder in addition to depression (e.g., panic disorder), that condition's symptoms might overshadow the depression and cause a missed diagnosis. Finally, depression may simulate other psychiatric disorders (e.g., dementia) and thus confound the diagnostic process. One study found that recognition of depression by primary care physicians was only $29 \%$ in patients with comorbid general medical illness versus $67 \%$ in those without comorbidity. ${ }^{87}$

Financial considerations also may intrude: for example, reluctance to diagnose depression in a patient with little or no mental health third-party coverage because the patient may be unable to obtain care once the diagnosis is made. The physician may find it necessary to treat specific physical symptoms (e.g., insomnia, pain, fatigue) 
because these nonpsychiatric disorders will be covered. Rost and colleagues describe some of the reasons that physicians deliberately miscode diagnoses. ${ }^{80}$

\section{Treatment Barriers}

Some patients may be unwilling to accept a diagnosis of depression and thus will not accept any treatment. Others may be hesitant about beginning specific treatments. Some patients are reluctant to take antidepressants for fear of "becoming addicted," "needing a crutch," taking "mind-control drugs," or for other reasons; some may then be prone to mislabel pretreatment symptoms as drug-related after beginning on antidepressants. ${ }^{88}$ Other patients will avoid psychotherapy, fearing it to be too intrusive, complicated, lengthy, expensive, or overly focused on childhood experiences. Patients who begin treatment may be dissuaded by unexpected or unpleasant side effects of medications, delay in sufficient improvement, or difficulty in forming an alliance with a psychotherapist. Patients also may be reluctant to see a mental health specialist even if such services are available.

Even if patients initially agree to treatment, they must adhere to enough of a treatment plan to make it likely that outcomes will be improved. Many patients discontinue their medications within the first month. ${ }^{89} \mathrm{~Pa}-$ tient education improves adherence for those with depression in almost all studies in which it has been examined, as it does for many other medical conditions. The difference between outcomes of adherent and nonadherent patients may be considerable, equivalent to the difference between active antidepressant use and a placebo. ${ }^{90}$

Several physician-related barriers exist as well. As noted above, too many physicians interpret a depression as "appropriate" for the patient's circumstances and thus not in need of treatment. At other times, physicians will fail to appreciate the duration or severity of a depression and take an inappropriately expectant approach, withholding treatment for a certain time or unless certain conditions are met.

Even when the physician decides that treatment is warranted, the treatment offered may be suboptimal. Antidepressants may be prescribed in inadequate doses or for periods too short to be effective. A common problem is that a physician reacts to reports of side effects that occur shortly after starting an antidepressant by discontinuing the drug, lowering the dose below the therapeutic range, or switching to another drug. This may lead to a series of inadequate drug trials, resulting in multiple side effects but no improvement. Not uncommonly, the patient may decide to forgo further treatment.

Similar problems may occur with psychotherapy. Because few physicians are trained in the empirically proven effective psychotherapies, brief office counseling may be offered. This results in psychotherapy of inadequate intensity or duration. Even if referral is made to a mental health practitioner, that clinician too may undertake a form of psychotherapy (most commonly psychodynamic psychotherapy) that has not been proved to be efficacious for depression.

A number of health care system factors also serve as barriers to treatments. Third-party coverage for mental health care may be limited or nonexistent. Thus, patients may be covered for only a certain number, duration, or frequency of psychotherapy sessions. Even though the empirically validated psychotherapies generally require only 12 to 20 sessions, this often exceeds a health care plan's limits for psychotherapy. Visits for medication checks, even if provided by the primary care physician, may be considered part of the mental health benefit, so the lowered limits on visits, percentage of reimbursement, or total costs covered and any higher copayments may apply. In some settings in which mental health care is carved out, primary care physicians may not be reimbursed for any treatment of depression they provide.

In many areas (particularly rural), availability of mental health professionals may be limited, and patients must make do with whatever care the primary care physician or a limited mental health clinician community can provide. Patients who are covered by mental health carve outs must accept the care provided through that system, even if it is difficult to access or limited in provision.

It is likely that the use of newer antidepressants, despite being more expensive than older agents, results in equal or lower total costs overall by reducing adverse drug reactions, drug monitoring, and hospitalizations for worsened depression or other adverse events (e.g., severe side effects, suicide attempts). ${ }^{91,92}$ Nonetheless, some managed care organizations continue to influence treatment by formulary restrictions of antidepressant drugs, often in favor of older, less expensive, and less safe choices. Managed care organizations also may influence physician behavior by discouraging appropriate specialty referrals, thus reducing access of depressed patients in need of specific psychotherapies or more expert psychopharmacologic care.

Barriers to recognition, diagnosis, and optimal treatment are summarized in Table 3.

\section{ACTIVITIES TO REDUCE BARRIERS}

Many professional organizations and advocacy groups have drawn attention to the undertreatment of depression and the need to increase public and professional awareness. For example, a consensus panel sponsored by the National Depression and Manic-Depressive Association issued a report on undertreatment of depression, ${ }^{93}$ proposing five immediate steps to reduce the gap between knowledge about depression and actual treatment received: enhancing the role of patients and families, developing performance standards for behavioral health care, increasing provider knowledge and awareness, enhancing collaboration among providers for disease management, and conducting research for new treatments. 
Table 3. Some Barriers to Recognition, Diagnosis, and Optimal Treatment of Depression*

\begin{tabular}{lll}
\hline \hline Patient Factors & \multicolumn{1}{c}{ Physician Factors } & Health Care System Factors \\
\hline $\begin{array}{l}\text { Denial, minimization of symptoms, } \\
\text { believing can handle by self }\end{array}$ & $\begin{array}{c}\text { Not believing it is real illness, very serious, } \\
\text { or particulary distressing } \\
\text { Not seeing as medical in nature }\end{array}$ & Time constraints \\
Concerns about confidentiality & Medicalization of symptoms & Other pressing clinical issues \\
Not ready to accept diagnosis & Fear of offending patient & Limitations on third-party coverage \\
Fear of treatments or nonadherence & Knowledge deficit regarding diagnosis & Limited treatment resource availability \\
with treatment plan & and/or treatment & Restrictions on access to particular \\
Stigma of mental health treatment & Diagnosis obscured by comorbidity & Fragmentation of care
\end{tabular}

* Modified from Goldman. ${ }^{82}$

Many attempts have been made to identify critical skills and knowledge for primary care physicians. A model curriculum for physicians to diagnose and treat the most common mental and behavioral disorders seen in primary care settings has been developed by a task force of the Society for General Internal Medicine, with input from the American College of Physicians, the American Academy of Physician and Patient, the American Association of Medicine and Psychiatry, and the American Psychiatric Association. ${ }^{94}$ Major depression and dysthymia are included among the "mental disorders of central importance in primary care."

The importance of family physicians has been highlighted by publications such as a White paper of the American Academy of Family Physicians that referred to mental health services as "an essential component of comprehensive primary medical care."95 A model curriculum for the psychiatric training of family practitioners also has been developed. ${ }^{96}$

The primary care version of DSM-IV is designed to assist in the recognition and diagnosis of depression; practice guidelines for treating major depression in adults in primary care settings have been developed by the AHCPR. The American Psychiatric Association, with input from many medical organizations, also has developed treatment guidelines for major depression in adults, which are primarily directed at psychiatrists, but may be helpful to primary care physicians as well. ${ }^{97}$

An example of an approach to teaching the interviewing skills needed to increase recognition of depression is McWhinney's "patient-centered" and "problem-based" approach to interviewing, which has been extensively tested in Great Britain. ${ }^{98}$ These techniques may be taught to trainees or self-taught by practicing physicians. Evidence suggests that depression-recognition skills are improved and that the patients of physicians using these techniques have better clinical outcomes. ${ }^{99}$

Once the diagnosis is made and treatment initiated, so-called disease management programs may assist with clinical monitoring and patient adherence. Several pharmaceutical manufacturers and managed care entities have developed proprietary programs to help educate patients about depression, assist physicians in tracking the course of a patient's illness, and increase treatment adherence. The effectiveness of such programs is not currently known. Model programs such as those of Schulberg et al., ${ }^{74}$ Katon et al. ${ }^{77}$ and others, which have been or are being rigorously studied, provide additional, on-site staff for treatment as well as physician education and guideline utilization.

For the past 10 years, the National Institute of Mental Health has operated the Depression Awareness, Recognition, and Treatment program, ${ }^{100}$ which includes educational components directed to the public, professionals, and employers. More recently, it has emphasized the importance of recognizing and treating depression when it co-occurs with other general medical disorders. A similar, nongovernmental approach was the Defeat Depression Campaign, a public and professional education campaign undertaken jointly by the Royal College of Psychiatrists and the Royal College of General Practitioners that ran in the United Kingdom from 1992 through 1996. The effects of the campaign are currently being evaluated. ${ }^{101}$

Other campaigns that emphasize public awareness include National Depression Screening Day (part of National Mental Illness Awareness Week) each October and the National Public Education Campaign on Clinical Depression, a public service campaign launched in 1993. The latter is sponsored by the National Mental Health Association and cosponsored by more than 100 professional groups and advocacy groups. The National Association for Research on Schizophrenia and Affective Disorders (NAR$\mathrm{SAD}$ ) also has a public education campaign on depression, whose slogan is "depression is a flaw in chemistry, not character."

The American Medical Association has adopted policies that emphasize physician and public education, the need for outcomes research, and the importance of equivalent third-party coverage for psychiatric disorders. The following statements, recommended by the Council on Scientific Affairs, were adopted as AMA Policy at the AMA Interim Meeting in December 1997: (1) The AMA encourages medical schools, primary care residencies, and other training programs as appropriate to include the appropriate knowledge and skills to enable graduates to recognize, diagnose, and treat depression, both when it occurs by 
itself and when it occurs with another general medical condition. (2) The AMA also encourages all physicians providing clinical care to acquire the same knowledge and skills. (3) The AMA encourages additional research into the course and outcomes of patients with depression who are seen in general medical settings and into the development of clinical and systems approaches designed to improve patient outcomes. Furthermore, any approaches designed to manage care by reduction in the demand for services should be based on scientifically sound outcomes research findings. (4) The AMA fully supports equivalent third-party coverage for all psychiatric disorders, including depression, with that for other medical disorders, and it strongly opposes any arbitrary restrictions or limitations on the provision of mental health services. (5) The AMA will work with the National Institute on Mental Health and appropriate medical specialty and mental health advocacy groups to increase public awareness about depression, to reduce the stigma associated with depression, and to increase patient access to quality care for depression.

\section{SUMMARY}

Depression, a commonly occurring disorder in the general population, is seen even more frequently in general medical settings and is associated with marked individual and family suffering, an elevated risk of suicide, functional impairment, and a high economic toll in health care costs and lost productivity. Diagnostic criteria are well established, and a number of screening tools exist for use in symptomatic patients. Highly effective psychopharmacologic and psychotherapeutic treatments are available. Most cases of depression seen in general medical settings are milder forms of the illness than are typically seen in specialty settings, and they are frequently amenable to treatment in the primary care setting by those with appropriate expertise.

Depression frequently co-occurs with a number of chronic general medical illnesses, and such comorbidity may complicate the recognition of a depressive illness. Co-occurring depression often impairs patient adherence to medical care and may seriously worsen the course and prognosis of both conditions. Therefore, it is essential to diagnose and treat such co-occurring depression.

Only about half of all cases of depression are recognized and diagnosed in primary care settings, although such unrecognized cases generally are milder and more self-limited in nature. Improved recognition by physicians is largely associated with attitudes about depression and the use of certain specific interviewing skills. Even when cases are recognized, both pharmacologic and psychotherapeutic treatments provided often fall short of existing practice guidelines. When practice guidelines are followed, patient outcomes are quite good.

Barriers to diagnosing and treating depression in general medical settings include those related to stigma; patient somatization and denial; time; patient adherence to treatment; physician knowledge and skill deficits; lack of availability of providers and specific treatments; limitations of third-party coverage; and restrictions on specialist, drug, and psychotherapeutic care. A number of programs are under way to reduce these barriers, but undertreatment remains a serious problem.

Members and staff of the Council on Scientific Affairs at the time this report was prepared: Ronald M. Davis, MD, Detroit, Mich (Chair); Joseph A. Riggs, MD, Haddon Fields, NJ (ChairElect); Roy D. Altman, MD, Miami, Fla; Hunter C. Champion, New Orleans, La; Scott D. Deitchman, MD, MPH, Decatur, Ga; Myron Genel, MD, New Haven, Conn; John P. Howe III, MD, San Antonio, Tex; Mitchell S. Karlan, MD, Los Angeles, Calif; Mohamed Khaleem Khan, MD, PhD, Boston, Mass; Nancy $H$. Nielsen, MD, PhD, Buffalo, NY; Michael A. Williams, MD, Baltimore, Md; Donald C. Young, MD, lowa City, lowa; Linda $B$. Bresolin, PhD (CSA Secretary), Barry D. Dickinson, PhD (CSA Assistant Secretary), Chicago, Ill; Larry S. Goldman, MD (Department of Psychiatry, University of Chicago).

\section{REFERENCES}

1. Council on Scientific Affairs, American Medical Association. Informational Reports. Comorbidity; Epidemiology of Depression; Diagnosis of Depression; Treatment of Depression. Presented at the American Medical Association Annual Meeting, Chicago, Ill, June 23-27, 1991.

2. Robins LW, Helzer JE, Weissman MM, et al. Lifetime prevalence of specific psychiatric disorders in three sites. Arch Gen Psychiatry. 1984;41:949-58.

3. Kessler RC, McGonagle KA, Zhao S, et al. Lifetime and 12-month prevalence of psychiatric disorders in the United States: results from the National Comorbidity Survey. Arch Gen Psychiatry. 1994;51:8-19.

4. Sansone R, Sansone L. Dysthymic disorder: the chronic depression. Am Fam Physician. 1996;53:2588-94.

5. Myer J, Weissman MM, Tischler GL, et al. Six-month prevalence of psychiatric disorders in three communities: 1908 to 1982 . Arch Gen Psychiatry. 1984;41:959-67.

6. Montano CB. Recognition and treatment of depression in a primary care setting. J Clin Psychiatry. 1994;55(12, suppl):18-34.

7. Katon W, Schulberg H. Epidemiology of depression in primary care. Gen Hosp Psychiatry. 1992;14:237-47.

8. Barrett JE, Barrett JA, Oxman TE, et al. The prevalence of psychiatric disorders in a primary care practice. Arch Gen Psychiatry. 1988;45:1100-6.

9. Schulberg HC, Madonia MJ, Block MR, et al. Major depression in primary care practice: clinical characteristics and treatment implications. Psychosomatics. 1995;36:129-37.

10. American Psychiatric Association. Diagnostic and Statistical Manual of Mental Disorders. 4th ed. Washington, DC: American Psychiatric Press; 1994:320-7.

11. Coghill SR, Caplan GR. Impact of maternal postnatal depression on cognitive development of young children. BMJ. 1986;292: 116-7.

12. Wells KB, Stewart A, Hays RD, et al. The functioning and wellbeing of depressed patients: results from the Medical Outcomes Study. JAMA. 1989;62:914-9.

13. Murray CJL, Lopez AD, eds. The Global Burden of Disease. Cambridge, Mass: Harvard University Press; 1996:21.

14. Greenberg PE, Stiglin LE, Finkelstein SN, et al. The economic burden of depression in 1990. J Clin Psychiatry. 1993;54:405-18. 
15. Greenberg PE, Kessler RC, Nells TL, et al. Depression in the workplace: an economic perspective. In: Feighner JP, Boyer WF, eds. Selective Serotonin Uptake Inhibitors: Advances in Basic Research and Clinical Practice. 2nd ed. New York, NY: John Wiley and Sons; 1996.

16. Callahan CM, Kesterson JO, Tierney WM. Association of symptoms of depression with diagnostic test charges among older adults. Ann Intern Med. 1997;126:426-32.

17. Henks HJ, Katzelnick DJ, Kobak KA, et al. Medical costs attributed to depression among patients with a history of high medical expenses in a health maintenance organization. Arch Gen Psychiatry. 1996;53:899-904.

18. Unutzer J, Patrick DL, Simon G, et al. Depressive symptoms and the cost of health services in HMO patients aged 65 and older: a 4-year prospective study. JAMA. 1997;277:1618-23.

19. Simon GE, VonKorff M, Barlow W. Health care costs of primary care patients with recognized depression. Arch Gen Psychiatry. 1995;52:850-6.

20. US Preventive Services Task Force. Guide to Clinical Preventive Services. 2nd ed. Baltimore, Md: Williams and Wilkins; 1996.

21. Periodic health examination, 1990 update, 2: early detection of depression and prevention of suicide. Can Med Assoc J. 1990; 142:1233-8.

22. Goldberg DP. The Detection of Psychiatric Illness by Questionnaire. London, UK: Oxford University Press; 1972.

23. Beck AT, Beck RW. Screening depressed patients in family practice: a rapid technic. Postgrad Med. 1972;52:81-5.

24. Derogatis LR. The SCL-90-R. Baltimore, Md: Clinical Psychometrics Research; 1975.

25. Rush AJ, Gullion CM, Basco MR, et al. The Inventory of Depressive Symptomatology (IDS): psychometric properties. Psychol Med. 1996;26:477-86.

26. Zung WKW. A self-rating depression scale. Arch Gen Psychiatry. 1965;12:63-70.

27. Radloff LS. The CES-D scale: a self-report depression scale for research in the general population. Appl Psychol Measure. 1992;7: 343-51.

28. Sheikh JI, Yesavage JA. Geriatric Depression Scale (GDS): recent evidence and development of a shorter version. Clin Gerontol. 1986;5:165-73.

29. Lyness JM, Noel TK, Cox C, et al. Screening for depression in elderly primary care patients. Arch Intern Med. 1997;157:449-54.

30. Weissman M, Olfson M, Leon AC, et al. Brief diagnostic interviews (SDDS-PC) for multiple mental disorders in primary care. Arch Fam Med. 1995;4:220-7.

31. Spitzer RL, Williams JBW, Kroenke K, et al. Utility of a new procedure for diagnosing mental disorders in primary care: the PRIME-MD 1000 study. JAMA. 1994;272:1749-56.

32. American Psychiatric Association. Diagnostic and Statistical Manual of Mental Disorders, 4th ed. Primary Care Version. Washington, DC: American Psychiatric Press; 1995.

33. Wolraich ML, Felice ME, Drotar D, eds. Diagnostic and Statistical Manual for Primary Care, Child and Adolescent Version. Elk Grove Village, Ill: American Academy of Pediatrics; 1996.

34. Ustun B, Goldberg D, Cooper J, et al. New classification for mental disorders with management guidelines for use in primary care, the ICD-10 PHC chapter 5. Br J Gen Pract. 1995;45: 211-5.

35. Glassman AH. Cigarette smoking: implications for psychiatric illness. Am J Psychiatry. 1993;150:546-51.

36. Stoudemire A, Fogel BS. Principles of Medical Psychiatry. 2nd ed. Orlando, Fla: Grune \& Stratton; 1993.

37. Rundell JR, Wise MG, eds. American Psychiatric Press Textbook of Consultation-Liaison Psychiatry. Washington, DC: American Psychiatric Press; 1996.

38. Nesse R, Finlayson R. Management of depression in patients with coexisting medical illness. Am Fam Physician. 1996;53:2123-33.

39. Caine ED, Lyness JM, Conwell Y. Diagnosis of late-life depres- sion: preliminary studies in primary care settings. Am J Geriatr Psychiatry. 1996;4(suppl):S45-50.

40. Callahan CM, Hendrie HC, Tierney WM. The recognition and treatment of late-life depression: a view from primary care. Int $\mathrm{J}$ Psychiatry Med. 1996;26:155-71.

41. Covinsky KE, Fortinsky RH, Palmer RM, et al. Relation between symptoms of depression and health status outcomes in acutely ill hospitalized older persons. Ann Intern Med. 1997;126:417-25.

42. Quill TE. Doctor, I want to die. Will you help me? JAMA. 1993; 270:870-3.

43. Masand PS, Chengappa KNR, Edwards W. Somatic treatments. In: Goldman LS, Wise T, Brody D, eds. Psychiatry for Primary Care Physicians. Chicago, Ill: American Medical Association; 1998:331-64.

44. Jarrett RB, Rush AJ. Short-term psychotherapy of depressive disorders: current status and future directions. Psychiatry. 1994;57:115-32.

45. McLean PD, Hakstian AR. Clinical depression: comparative efficacy of outpatient treatments. J Consult Clin Psychol. 1979;47: 818-36.

46. Shea MT, Elkin E, Hirschfeld RMA. Psychotherapeutic treatment of depression. In: Frances AJ, Hales RE, eds. Review of Psychiatry. Washington, DC: American Psychiatric Press; 1988:235-55.

47. Brodaty H, Andrews G. Brief psychotherapy in family practice: a controlled prospective intervention trial. $\mathrm{Br} J$ Psychiatry. 1983;143:11-9.

48. Mynors-Wallis LM, Gath DH, Lloyd-Thomas AR, et al. Randomised controlled trial comparing problem-solving treatment with amitriptyline and placebo for major depression in primary care. BMJ. 1995;310:441-5.

49. Clarkin JF, Pilkonis PA, Magruder KM. Psychotherapy of depression: implications for reform of the health care system. Arch Gen Psychiatry. 1996;53:717-23.

50. Kupfer DJ, Frank E, Perel JM, et al. Five-year outcome for maintenance therapies in recurrent depression. Arch Gen Psychiatry. 1992;49:769-73.

51. Frank E, Kupfer DJ, Wagner EF, et al. Efficacy of interpersonal psychotherapy as a maintenance treatment of recurrent depression: contributing factors. Arch Gen Psychiatry. 1991;48:1053-9.

52. Agency for Health Care Policy and Research. Depression in Primary Care. Washington, DC: US Government Printing Office; 1993.

53. Regier DA, Narrow WE, Rae DS, et al. The de facto US mental and addictive disorders service system: Epidemiologic Catchment Area prospective 1-year prevalence rates of disorders and services. Arch Gen Psychiatry. 1993;50:85-94.

54. Goldberg D. Epidemiology of mental disorders in primary care settings. Epidemiol Rev. 1995;7:182-90.

55. Wells KB, Hays RD, Burnam A, et al. Detection of depressive disorder for patients receiving prepaid or fee-for-service care: results from the Medical Outcomes Study. JAMA. 1989;262:3298-302.

56. Wells KB. Depression in medical settings: implications of three health policy studies for consultation-liaison psychiatry. Psychosomatics. 1994;35:279-96.

57. Badger LW, deGruy FV, Hartman J, et al. Psychosocial interest, medical interviews, and the recognition of depression. Arch Fam Med. 1994;3:899-907.

58. Robbins JM, Kirmayer LJ, Cathbras P, et al. Physician characteristics and the recognition of depression and anxiety in primary care. Med Care. 1994;32:795-812.

59. Simon GE, VonKorff M. Recognition, management, and outcomes of depression in primary care. Arch Fam Med. 1995;4:99-105.

60. Tiemens BG, Ormel J, Simon GE. Occurrence, recognition, and outcome of psychological disorders in primary care. Am J Psychiatry. 1996;153:636-44.

61. Katon W, Gonzales J. A review of randomized trials of psychiatric consultation-liaison studies in primary care. Psychosomatics. $1994 ; 35: 268-78$. 
62. Schulberg HC, Magruder KM, deGruy F. Major depression in primary medical care practice: research trends and future priorities. Gen Hosp Psychiatry. 1996;18:395-406.

63. Higgins ES. A review of unrecognized mental illness in primary care. Arch Fam Med. 1994;3:908-17.

64. Chang G, Wamer V, Weissman MM. Physicians' recognition of psychiatric disorders in children and adolescents. Am J Dis Child. 1988; 142:736-9.

65. Costello EJ, Edelbrock C, Costello AJ, et al. Psychopathology in pediatric primary care: the new hidden morbidity. Pediatrics. 1988;82:415-24.

66. Canning EH, Hanser SB, Shade KA, et al. Mental disorders in chronically ill children: parent-child discrepancy and physician identification. Pediatrics. 1992;90:692-6.

67. Lavigne JV, Binns HJ, Christoffel KK, et al. Behavioral and emotional problems among preschool children in pediatric primary care: prevalence and pediatricians' recognition. Pediatrics. 1993; 91:649-55.

68. Katon W, Von Korff M, Lin E, et al. Adequacy and duration of antidepressant treatment in primary care. Med Care. 1992;30: 67-76.

69. Wells KB, Sturm R, Sherbourne CD, Meredith LS. Caring for Depression. Cambridge, Mass: Harvard University Press; 1996.

70. Schulberg HC, Block MR, Madonia MT, et al. The 'usual' care of major depression in primary care practice. Arch Fam Med. 1997; 6:334-9.

71. Meredith LS, Wells KB, Kaplan SH. Counseling provided for depression: role of clinician specialty and payment system. Arch Gen Psychiatry. 1996;53:905-12.

72. Katzelnick DJ, Kobak KA, Greist JH, et al. Effect of primary care treatment of depression on service use by patients with high medical expenditures. Psychiatr Serv. 1997;48:59-64.

73. Sturm R, Wells KB. How can care for depression become more cost-effective? JAMA. 1995;273:51-8.

74. Schulberg HC, Block MR, Madonia MJ, et al. Treating major depression in primary care practice. Arch Gen Psychiatry. 1996;53: 913-9.

75. Schulberg HC, Block MR, Madonia MJ, et al. Applicability of clinical pharmacotherapy guidelines for major depression in primary care settings. Arch Fam Med. 1995;4:106-12.

76. Coulehan JL, Schulberg HC, Block MR, et al. Treating depressed primary care patients improves their physical, mental, and social functioning. Arch Intern Med. 1997;157:1113-20.

77. Katon W, Robinson P, Von Korff M, et al. A multifaceted intervention to improve treatment of depression in primary care. Arch Gen Psychiatry. 1996;53:924-32.

78. Katon W, Von Korff M, Lin E, et al. Collaborative management to achieve treatment guidelines: impact on depression in primary care. JAMA. 1995;273:1026-31.

79. Von Korff M, Katon W, Bush T, et al. Treatment costs, cost offset, and cost-effectiveness of collaborative management of depression. Psychosomatic Med. 1998;60:143-9.

80. Rost K, Smith R, Matthews DB, et al. The deliberate misdiagnosis of major depression in primary care. Arch Fam Med. 1994;3: 333-7.
81. Docherty JP. Barriers to the diagnosis of depression in primary care. J Clin Psychiatry. 1997;58(suppl 1):5-10.

82. Goldman LS. Psychiatry in primary care: possible roles for organized medicine. Psychiatr Ann. 1997;27:425-9.

83. Cohen-Cole S. The Medical Interview: The Three Function Approach. St. Louis, Mo: Mosby-Yearbook; 1991.

84. Barsky AJ, Borus JB. Somatization and medicalization in the era of managed care. JAMA. 1995;274:1931-4.

85. Goldberg D. Detection and assessment of emotional disorders in a primary care setting. Int $\mathrm{J}$ Ment Health. 1979;8:30-48.

86. Eisenberg L. Treating depression and anxiety in primary care: closing the gap between knowledge and practice. N Engl J Med. 1992;326:1080-3.

87. Tylee AT, Freeling P, Kerry S. Why do general practitioners recognize major depression in one woman patient yet miss it in another? Br J Gen Pract. 1993;43:327-30.

88. Rollman BL, Block MR, Schulberg HC. Symptoms of major depression and tricyclic side effects in primary care patients. J Gen Intern Med. 1997;12:284-91.

89. Simon GE, Lin EH, Katon W, et al. Outcomes of "inadequate" antidepressant treatment. J Gen Intern Med. 1995;10:663-70.

90. Basco MR, Rush AJ. Compliance with pharmacotherapy in mood disorders. Psychiatric Ann. 1995;25:269-70,276,278-9.

91. Simon GE, VonKorff M, Heiligenstein JH, et al. Initial antidepressant choice in primary care: effectiveness and cost of fluoxetine vs tricyclic antidepressants. JAMA. 1996;275:1897-902.

92. Sclar D, Robison LM, Skaer TL, et al. Antidepressant pharmacotherapy: economic outcomes in a health maintenance organization. Clin Ther. 1994;16:715-30.

93. Hirschfield RMA, Keller MB, Panico S, et al. The National Depressive and Manic-Depressive Association consensus statement on the undertreatment of depression. JAMA. 1997;277:333-40.

94. Cole SA, Sullivan M, Kathol R, et al. A model curriculum for mental disorders and behavioral problems in primary care. Gen Hosp Psychiatry. 1995; 17:13-8.

95. Commission on Health Care Services. White Paper on the Provision of Mental Health Care Services by Family Physicians. Kansas City, Mo: The American Academy of Family Physicians; 1994.

96. Jones LR, Knopke HJ, Parlour RR, et al. A curriculum for the psychiatric training of family physicians. Gen Hosp Psychiatry. 1981;3:189-98.

97. American Psychiatric Association Work Group on Major Depressive Disorder. Practice guideline for major depressive disorder in adults. Am J Psychiatry. 1993;150(suppl):1-26.

98. Brown J, Stewart M, McCracken E, et al. The patient-centered clinical method, II: definition and application. Fam Pract. 1986;3:75-9.

99. Gask L, Goldberg D. Impact on patient care, satisfaction, and clinical outcome of improving the psychiatric skills of general practitioners. Eur J Psychiatry. 1993;7:203-18.

100. Regier DA, Hirschfield RMA, Goodwin FK, et al. The NIMH Depression Awareness, Recognition, and Treatment Program: structure, aim, and scientific basis. Am J Psychiatry. 1988;145:1351-7.

101. Paykel ES, Tylee A, Wright A, et al. The Defeat Depression Campaign: psychiatry in one public arena. Am J Psychiatry. 1997; 154(suppl):59-65. 